\title{
Multiple Sclerosis-Associated Fatigue during Disease-Modifying Treatment with Natalizumab, Interferon-Beta and Glatiramer Acetate
}

\author{
Murat Yildiz Barbara Tettenborn Norman Putzki \\ Department of Neurology, Cantonal Hospital St. Gallen, St. Gallen, Switzerland
}

Dear Sir,

Fatigue is one of the most common symptoms in multiple sclerosis (MS) and can result in severe impairment of quality of life [1]. Fatigue is likely multidimensional but subtle central inflammatory activity may play a role [2]. Disease modifying treatment with interferon- $\beta$ (IFN) and glatiramer acetate (GA) successfully reduces inflammatory disease activity but does not appear to reduce levels of fatigue [3]. Natalizumab (NTZ) - a monoclonal antibody against Very-Late-ActivationAntigen 4 - reduces leukocyte migration across the blood-brain barrier and thereby unfolds strong effects on central inflammation (i.e. contrast enhancing lesions or new lesions on MRI) [4]. The objective of this study was to compare prevalence and severity of MS-associated fatigue in patients treated with NTZ in comparison to IFN and GA.

This was a cross-sectional case control study. Forty-nine consecutive patients treated with NTZ (all patients treated at our center at the time of study) were compared to $320 \mathrm{MS}$ patients in our database who have been investigated for fatigue before NTZ was licensed. Fifty-three patients met the inclusion criteria (relapsing patients treated with IFN or GA) and were matched for age, gender and disability $(\mathrm{n}=$ 31 (58.5\%) treated with IFN, $\mathrm{n}=22(41.5 \%)$ treated with GA). The study was conduct- ed in accordance with requirements of the local Ethics committee. Fatigue was measured with the Modified Fatigue Impact Scale (MFIS) [5] and the Fatigue Severity Scale (FSS) [6]. Mean FSS scores $\geq 5$ indicate 'severe fatigue' (FSS $\geq 5$ ) while scores $<4$ indicate 'no fatigue' (scores $\geq 4$ to $<5$ indicate 'borderline fatigue') [7]. The MFIS is a 21-item questionnaire ranging from 0 to 48 (higher scores indicating more fatigue). A cut-off score of 38 discriminates 'severely fatigued' from 'nonfatigued' patients [8]. Means and SDs were used to describe patients' characteristics. Categorical data were compared with the $\chi^{2}$ test or Fisher's exact test. By means of the Mann-Whitney U test, we compared the nonparametric data. We used logistic regression to investigate the influence of categorical variables on dichotomized $(<4$ vs. $\geq 4$ ) FSS scores. All tests have been performed two-sided. $\mathrm{p}<0.05$ was considered statistically significant. Analysis was performed with SPSS 17.0 (Chicago, Ill., USA).

Forty-nine patients were treated with NTZ (mean $37.0 \pm 9.9$ years, mean disease duration $8.0 \pm 4.5$ years, $84 \%$ females, mean EDSS $2.9 \pm 1.2$ ). In the matched control group, 53 patients were treated with IFN/GA (mean age $37.9 \pm 8.6$, mean disease duration $8.5 \pm 6.4$ years, $78 \% \mathrm{fe}$ males, mean EDSS $2.6 \pm 1.3$ ): $\mathrm{n}=2$ intramuscular IFN- $\beta$ 1a $30 \mu \mathrm{g}$ once weekly, $\mathrm{n}=$
6 s.c. IFN- $\beta 1 \mathrm{~b} 250 \mu \mathrm{g}$ every other day, $\mathrm{n}=$ 11 s.c. IFN- $\beta 1 \mathrm{a} 22 \mu \mathrm{g}$ or $\mathrm{n}=13$ IFN- $\beta 1 \mathrm{a} 44$ $\mu \mathrm{g}$ three times weekly and $\mathrm{n}=21$ GA 20 $\mathrm{mg}$ once daily s.c. Treatment duration was $18.3 \pm 8.4$ months for NTZ-treated patients and $29.1 \pm 15.8$ months for IFN/GA. Annualized relapse rate (ARR) was 0.2 in the NTZ group versus 0.5 in the IFN/GA group $(\mathrm{p}<0.001)$. Patients were treated before NTZ with: IFN $\mathrm{n}=37$ (75.5\%), GA $\mathrm{n}=5(10.2 \%)$, mitoxantrone $\mathrm{n}=2(4.1 \%)$, other treatments $\mathrm{n}=2(4.1 \%)$, no treatment $\mathrm{n}=3$ (6.1\%). Mean FSS score was $3.7 \pm 1.9$ with NTZ versus $4.9 \pm 0.8$ with IFN/GA $(\mathrm{p}=0.012)$ (no differences between IFN and GA). $51 \%$ of NTZ patients reported 'no fatigue' versus $13.2 \%$ with IFN/GA ( $p<$ 0.001 ). Prevalence of severe fatigue was $34.7 \%$ in the NTZ group compared to $51 \%$ for IFN/GA ( $p=0.041)$. 'Borderline fatigue' was $14.3 \%$ with NTZ and $35.8 \%$ for IFN/GA $(p=0.029)$. Mean total MFIS score was $32.6 \pm 20.9$ with NTZ and IFN/ GA with $47.8 \pm 13.7(\mathrm{p}<0.001)$. There was no significant difference between total MFIS GA $45.8 \pm 13.1$ and IFN $49.7 \pm$ 14.3. Fewer patients with NTZ suffered from severe fatigue (50 vs. $71 \%, \mathrm{p}=0.04$ ). Fatigue was less on all subscales of the MFIS for NTZ-treated patients (all p = 0.001 ). See figure 1 for detailed information on the subscales of MFIS. Results for fatigue assessed by means of MFIS corre-

\section{KARGER}

Fax +4161306 1234 E-Mail karger@karger.ch www.karger.com
Norman Putzki, MD

Department of Neurology, Multiple Sclerosis Outpatient Clinic Cantonal Hospital St. Gallen

Rorschacher Strasse 95, CH-9007 St. Gallen (Switzerland)

Tel.+41 71494 1669, E-Mail norman.putzki@kssg.ch 
Fig. 1. Mean total MFIS and subscale MFIS scores were compared between NTZ and INF/GA (all p $<0.001)$.

lated with FSS. Age, gender, disease duration, IFN or GA treatment and EDSS had no influence on fatigue levels as measured with FSS or MFIS.

This cross-sectional case-control study revealed that the prevalence and severity of fatigue during NTZ treatment was lower compared to IFN/GA treatment. Levels of fatigue in IFN/GA-treated patients in the database were comparable in the control group. The literature on a potential effect of IFN or GA on levels of fatigue is controversial $[9,3]$. Given the marked re-

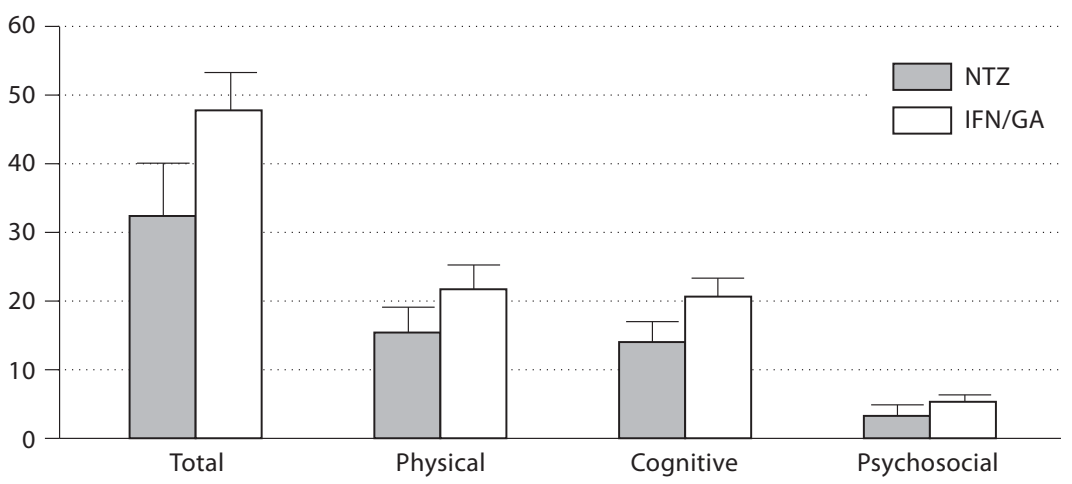

duction of clinical and MRI parameters for inflammatory activity in comparison to IFN and GA, this effect could be attributable to a more pronounced decrease of inflammatory CNS activity with NTZ. Our results in longer-term NTZ-treated patients complement results from a previous short-term prospective study [10]. Findings for the control group were similar to previous analyses from the same database [3]. Fatigue was independent from most important patient characteristics, which underlines that we examined a common construct of fatigue [3,8-10]. A reduction of fatigue during NTZ treatment represents a relevant, additional treatment benefit for improved quality of life. A randomized controlled trial is necessary to confirm our findings but conduction is currently not feasible due to restrictions for NTZ use.

\section{Disclosure Statement}

N.P. is an employee of Biogen Idec.

\section{References}

1 Fisk JD, Pontrefact A, Ritvo PG, et al: The impact of fatigue on patients with multiple sclerosis. Can J Neurol Sci 1994;21:9-14.

$\checkmark 2$ Heesen C, Nawrath L, Reich C, et al: Fatigue in multiple sclerosis: an example of cytokine mediated sickness behaviour? J Neurol Neurosurg Psych 2006;77:34-39.

-3 Putzki N, Katsarava Z, Vago S, et al: Prevalence and severity of multiple sclerosis associated fatigue. Eur Neurol 2008;59:136-142.

-4 Polman CH, O'Connor PW, Havrdova E, et al: A randomized, placebo controlled trial of natalizumab for relapsing multiple sclerosis. N Engl J Med 2006;354:899-910.
5 Bergamaschi R, Romani A, Versino M, et al: Clinical aspects of fatigue in multiple sclerosis. Funct Neurol 1997;12:247-251.

6 Krupp LB, LaRocca NG, Muir-Nash J, et al: The fatigue severity scale: application to patients with multiple sclerosis and systemic lupus erythematosus. Arch Neurol 1989;46: 1121-1123.

-7 Colosimo C, Millefiorini E, Grasso MG, et al: Fatigue in MS is associated with specific clinical feature. Acta Neurol Scand 1995;92: 353-355.
8 Flachenecker P, Kümpfel T, Kallmann B, et al: Fatigue in multiple sclerosis: a comparison of different rating scales and correlation to clinical parameter. Mult Scler 2002;8:523526.

9 Metz LM, Patten SB, Archibald CJ, et al: The effect of immunomodulatory treatment on multiple sclerosis fatigue. J Neurol Neurosurg Psych 2004;75:1045-1047.

10 Putzki N, Yaldizli Ö, Tettenborn B, et al: Multiple sclerosis associated fatigue during natalizumab treatment. J Neurol Sc 2009; 285:109-113. 